DOI: $10.2478 /$ rjp-2019-0013

Rom J Psychoanal 2019, 12(2):11

Rom J Psychoanal

\title{
OPENING WORD AT THE END OF THE TERM
}

Matei Georgescu ${ }^{2}$

We find ourselves at the end of my term as Director of the RJP.

Having witnessed its constant growth since it was founded in 2008, I feel satisfied looking back at the significant and fulfilled road, one which had national and international academic acknowledgement of the RJP as a main landmark, a goal gradually and continuously attained. And this included its indexation in prestigious data bases thanks to the quality of authors who published in the RJP's pages throughout the years.

Although the RJP began as an associate of the International Conference of Psychoanalysis organised by the Romanian Society of Psychoanalysis, it obtained autonomy as it evolved. In this order, the editorial dynamic was supported and allowed the RJP to develop in an unprecedented rhythm for autochthonous publications dealing with similar themes.

I am convinced that the RJP is on the right track under the direction of Gianina Micu, to whom I offer my gratitude for the joy of shared effort.

I also wish to thank my editorial colleagues, whose dedicated contribution and sustained effort made the RJP one of today's most important Romanian magazines in the field of psychology.

\footnotetext{
${ }^{2}$ Romanian Society of Psychoanalysis; matei.georgescu@yahoo.com
} 